\title{
Low energy recycling of ionic liquids via freeze crystallization during cellulose spinning
}

Liu, Yanrong; Meyer, Anne S.; Nie, Yi; Zhang, Suojiang; Thomsen, Kaj

Published in:

Green Chemistry

Link to article, DOI:

$10.1039 / \mathrm{c} 7 \mathrm{gc0} 0280 \mathrm{f}$

Publication date:

2018

Document Version

Peer reviewed version

Link back to DTU Orbit

Citation (APA):

Liu, Y., Meyer, A. S., Nie, Y., Zhang, S., \& Thomsen, K. (2018). Low energy recycling of ionic liquids via freeze crystallization during cellulose spinning. Green Chemistry, 20(2), 493-501. https://doi.org/10.1039/c7gc02880f

\section{General rights}

Copyright and moral rights for the publications made accessible in the public portal are retained by the authors and/or other copyright owners and it is a condition of accessing publications that users recognise and abide by the legal requirements associated with these rights.

- Users may download and print one copy of any publication from the public portal for the purpose of private study or research.

- You may not further distribute the material or use it for any profit-making activity or commercial gain

- You may freely distribute the URL identifying the publication in the public portal 


\title{
Low energy recycling of ionic liquids via freeze crystallization during cellulose spinning
}

\author{
Yanrong Liu, ${ }^{a, b, c}$ Anne S. Meyer, ${ }^{c}$ Yi Nie, ${ }^{a}$ Suojiang Zhang*a and Kaj Thomsen*b
}

A new method for recycling ionic liquids (ILs) from a cellulose spinning process is suggested. The method involves the combination of freeze crystallization and evaporation of $\mathrm{H}_{2} \mathrm{O}$ from IL+ $\mathrm{H}_{2} \mathrm{O}$ mixtures to recycle the ILs. Processes with EmimAc and EmimDep were used as references to develop this IL recycling method. EmimAc +12.5 wt $\% \mathrm{H}_{2} \mathrm{O}$ and EmimDep +4 wt $\% \mathrm{H}_{2} \mathrm{O}$ were selected for a quantitative mass and energy analysis of the cellulose spinning and IL recycling process (the maximal initial $\mathrm{H}_{2} \mathrm{O}$ levels in the ILs+ $\mathrm{H}_{2} \mathrm{O}$ mixtures for cellulose dissolution were determined experimentally). The energy requirement for the freeze crystallization+evaporation method was compared to evaporation only for recycling of EmimAc and EmimDep. To produce 1 kg dry cellulose fiber, $45.4 \mathrm{MJ}$ and $62.6 \mathrm{MJ}$ are required for recycling EmimAc and EmimDep respectively by the freeze crystallization+evaporation recycling method. Using evaporation only, 66.9 $\mathrm{MJ}$ is required for EmimAc recycling and $99.9 \mathrm{MJ}$ for EmimDep recycling per kg cellulose fiber produced. Thus, to fabricate 1 kg dry cellulose fiber using freeze crystallization+evaporation rather than evaporation, $21.5 \mathrm{MJ}$ can be saved for EmimAc and 37.3 MJ for EmimDep recycling. We also show that compared to a classical Lyocell fiber production method using $\mathrm{N}$-methylmorpholine-N-oxide (NMMO) as solvent, use of ILs is energy saving in itself. Hence, significantly less $\mathrm{H}_{2} \mathrm{O}$ is required in the cellulose spinning process with ILs than with $\mathrm{NMMO}$, and in turn less $\mathrm{H}_{2} \mathrm{O}$ has to be evaporated for the solvent recycling.

\section{Introduction}

The demand for textile fibers is increasing with the growth of the global population and the improvement of living standards. As commonly known, cellulose fibers, notably in the form of cotton, are crucially important for textile manufacturing all over the world. The classical industrial methods for producing cellulose fibers include the viscose process, the cuprammonium hydroxide process, and the NMMO process. ${ }^{1}$ However, these processes have the drawbacks of being far from eco-friendly. ${ }^{2}$

Ionic Liquids (ILS) can be considered green solvents for cellulose dissolution, and certain ILs have been shown to function well as solvents for spinning of cellulose fibers. ${ }^{1}$ Water is commonly used as an anti-solvent for coagulation of cellulose and for washing of the fibers to remove the IL after spinning. Hong et al. $^{3}$ introduced an air-gap spinning process to spin cellulose fibers in EmimAc using distilled water as coagulation solvent. Sun et al. ${ }^{4}$ prepared the cellulose fiber with raw pulp in $\mathrm{BmimCl}$ based on dry-jet and wet-spun methods and washing of the $\mathrm{BmimCl}$ by tap water. Luo et al. ${ }^{5}$ and Zhu et al. ${ }^{6}$ investigated wet-spinning of electrically conductive cellulose fibers in AmimCl and EmimAc respectively using deionized water to remove the solvents. However, in none of these studies, recycling of ILs from IL+ $\mathrm{H}_{2} \mathrm{O}$ mixtures after the fiber spinning was investigated. Despite the merits of ILs compared to organic solvents, including non-flammability and low vapor pressure, ${ }^{7}$ their cost is still a key inhibitory factor for their application in the cellulose fiber industry. Therefore, it is urgent and necessary

\footnotetext{
a. Beijing Key Laboratory of Ionic Liquids Clean Process, Key Laboratory of Green Process and Engineering, State Key Laboratory of Multiphase Complex Systems, Institute of Process Engineering, Chinese Academy of Sciences, P. O. Box 353, Beijing, 100190, China, E-mail: sjzhang@ipe.ac.cn.

b. Center for Energy Resources Engineering (CERE), Department of Chemical and Biochemical Engineering, Technical University of Denmark, Søltofts Plads 229, 2800, Lyngby, Denmark, E-mail: kth@kt.dtu.dk.

Center for Bioprocess Engineering, Department of Chemical and Biochemical Engineering, Technical University of Denmark, Søltofts Plads 227, 2800, Lyngby, Denmark, E-mail:am@kt.dtu.dk.

†Electronic Supplementary Information (ESI) available: EmimAc and EmimDep recycling processes by evaporation method. See DOI: 10.1039/x0xx00000x
}

to develop methods for IL recycling including feasible recovery of ILs from IL+ $\mathrm{H}_{2} \mathrm{O}$ systems in cellulose spinning processes.

Several IL recycling methods have been reported in the literature including membrane separation, ${ }^{8}$ evaporation, ${ }^{9}$ liquid-liquid extraction, ${ }^{10}$ centrifugal solvent-extraction, ${ }^{11}$ and Supercritical $\mathrm{CO}_{2}$ extraction. ${ }^{12}$ Membrane separation usually results in low IL recovery due to the high viscosity of IL mixtures, which is a barrier for industrial implementation. ${ }^{13}$ Evaporation of $\mathrm{H}_{2} \mathrm{O}$ from $\mathrm{IL}+\mathrm{H}_{2} \mathrm{O}$ mixtures has been used for recycling of the ILs, but this method is obviously energy consuming and the large energy requirement is a constraint for practical implementation. Liquid-liquid extraction by use of conventional organic solvents has also been suggested for recycling of ILs, but the use of organic solvents is not compatible with the "green" aspect of employing ILs. ${ }^{13}$

Based on our recent study determining the freezing points of a series of $\mathrm{IL}+\mathrm{H}_{2} \mathrm{O}$ mixtures, ${ }^{14}$ we hypothesized that freeze crystallization could be a feasible method for recovering ILs from dilute $\mathrm{IL}+\mathrm{H}_{2} \mathrm{O}$ solutions. Previous studies have shown that eutectic freeze crystallization is technically and economically feasible in cases where high product quality was required. Energy costs can be reduced by about $70 \%$ for certain systems by use of freeze crystallization compared to a three-stage evaporative crystallization. ${ }^{15}$ The present study was therefore undertaken to test the workability of this hypothesis in relation to minimizing energy use by employing freeze crystallization of $\mathrm{H}_{2} \mathrm{O}$ in the separation and recycling of ILs during a cellulose spinning process. The study included 1 . Cellulose solubility measurements for two selected ILs in mixtures with different water contents to identify the cellulose solubility in $\mathrm{IL}+\mathrm{H}_{2} \mathrm{O}$ mixtures. 2. Determination of the optimal initial water content from the cellulose solubility data. 3. Cellulose regeneration after spinning. 4. Prediction of the energy requirement for the IL recycling process. In addition, we included scanning electron microscopy (SEM) to assess the morphology of the cellulose fibers after spinning. Lastly, we compared the energy requirement of spinning using the ILs as solvents to the energy required in a classical cellulose spinning process employing NMMO as solvent. 


\section{Computational details}

The heat capacities $\left(C_{p}\right)$ of ILs were obtained from published experimental values: EmimAc $(298.15 \mathrm{~K} \text { to } 393.22 \mathrm{~K})^{16,17}$ and EmimDep ( $298 \mathrm{~K}$ to $343 \mathrm{~K})^{18}$. These values can also be found in the Ionic Liquids Database-IL Thermo (V2.0).19 A linear temperature dependency of heat capacity was calculated from these data for EmimAc and EmimDep as following: the slope, $a$, for the temperature dependency was calculated using equation 1. The heat capacities of EmimAc and EmimDep at the temperature $T$ were calculated by equation 2 . This equation was assumed to be valid at temperatures up to $393.15 \mathrm{~K}$ for EmimDep. The heat capacity of the cellulose, microcrystalline cellulose, MCC) was measured by Blokhin et al. ${ }^{20}$. Their $C_{p}$ data show an almost linear function of temperature in the temperature range relevant to our work. We used these data to fit parameters for MCC with equation 2. The specific enthalpy of EmimAc, EmimDep, and MCC at the temperature $T$ was calculated with equation 3 using a reference temperature $\left(T_{\text {ref }}\right)$ of $298.15 \mathrm{~K}$.

$$
\begin{aligned}
& a=\frac{C_{p, T_{2}}-C_{p, T_{1}}}{T_{2}-T_{1}} \\
& C_{p}=C_{p, 298.15 K}+a(T-298.15) \\
& H=\int_{T_{r e f}}^{T} C_{p} d T
\end{aligned}
$$

The specific enthalpy of water (liquid and vapor) was calculated using the NIST/ASME steam properties program (NIST standard reference database 10, version 3.0). For each step of the process (see later) the enthalpy of water vapor was calculated at the relevant temperature and pressure. A COSMORS evaluation of the water activity coefficient of the liquid solution leaving the evaporator at $393.15 \mathrm{~K}$ was used to predict the required pressure in the evaporator. The water activities $\left(a_{\mathrm{w}}\right)$ of the EmimAc+ $\mathrm{H}_{2} \mathrm{O}$ and EmimDep $+\mathrm{H}_{2} \mathrm{O}$ mixtures were determined from the water mole fraction of these mixtures and the predicted water activity coefficient. In each case, this water activity was multiplied with the saturation pressure of water, $0.199 \mathrm{MPa}$ at $393.15 \mathrm{~K}$ to get the required pressures of the evaporators. The specific enthalpies of water and water vapor at these conditions were calculated by the NIST/ASME steam properties program.

The heat capacity of liquid water cannot easily be measured below $273.15 \mathrm{~K}$. The heat capacity of liquid water in the freezing step was therefore set as the approximate value of $4.2 \mathrm{~kJ} /(\mathrm{kg} \cdot \mathrm{K})$. The water enthalpy in the freezing step was calculated by equation 3 with a reference temperature of $273.16 \mathrm{~K}$ (The triple point temperature of water). The value used for the heat of fusion of ice in this study was $333.55 \mathrm{~kJ} / \mathrm{kg} .{ }^{21}$ The heat capacity of ice was cited from Arshad et al., ${ }^{22}$ the value is 49.627 $\mathrm{J} /(\mathrm{mol} \cdot \mathrm{K})$, which corresponds to $2.76 \mathrm{~kJ} /(\mathrm{kg} \cdot \mathrm{K})$. Thus, the specific enthalpy of ice was calculated from equation $4 . T_{\text {ref }}$ in equation 4 is the reference temperature for water enthalpy, $273.16 \mathrm{~K}$.

$$
H_{\text {ice }}=\int_{T_{\text {ref }}}^{T} 2.76 d T-333.55=2.76\left(T-T_{\text {ref }}\right)-333.55
$$

\section{Results and discussion}

\subsection{MCC solubility in IL+ $\mathrm{H}_{2} \mathrm{O}$ mixture}

By increasing the water content in mixtures with EmimAc and EmimDep, the MCC solubility decreases significantly (Table 1 ). At $12.5 \mathrm{wt} \%$ water in EmimAc, the solubility of MCC is $12 \mathrm{wt} \%$ at $363.15 \mathrm{~K}$. At $4 \mathrm{wt} \%$ water in EmimDep the solubility of MCC is $8 \mathrm{wt} \%$ at $363.15 \mathrm{~K}$. A sudden decrease in MCC solubility takes place when this threshold water content is exceeded (Figure 1). The data are in agreement with previous reports showing that water influences cellulose solubility in ILs. ${ }^{23-25}$ It was shown earlier that EmimAc with 15 wt \% water can dissolve less than 1 wt\% cellulose. ${ }^{23}$ Olsson et al. reported that EmimAc is still an acceptable solvent for cellulose when mixed with certain amounts of water. ${ }^{25}$ Thus, solutions of EmimAc with 12.5 wt\% $\mathrm{H}_{2} \mathrm{O}$ and solutions of EmimDep with 4 wt\% $\mathrm{H}_{2} \mathrm{O}$ can be used as initial solvents for MCC in a cellulose spinning process.

Table $1 \mathrm{MCC}$ solubility in total mixtures at $363.15 \mathrm{~K}$.

\begin{tabular}{cc|cc}
\hline \multicolumn{2}{c|}{$\operatorname{EmimAC}(1)+\mathrm{H}_{2} \mathrm{O}(2)+\mathrm{MCC}(3)$} & \multicolumn{2}{|c}{$\operatorname{EmimDep}(1)+\mathrm{H}_{2} \mathrm{O}(2)+\mathrm{MCC}(3)$} \\
$w_{2}$ & $w_{3}$ & $w_{2}$ & $w_{3}$ \\
\hline 0.005 & $0.27^{26}$ & 0.0019 & $0.15^{26}$ \\
0.025 & 0.23 & 0.025 & 0.11 \\
0.05 & 0.16 & 0.04 & 0.08 \\
0.075 & 0.15 & 0.045 & 0.003 \\
0.10 & 0.14 & & \\
0.125 & 0.12 & & \\
0.13 & 0.004 & &
\end{tabular}

$w_{2}$ : weight fraction of $\mathrm{H}_{2} \mathrm{O}$ in solvent. $w_{3}$ : weight fraction of $\mathrm{MCC}$ in total mixture. The standard uncertainty of the weight fraction is 0.001 .

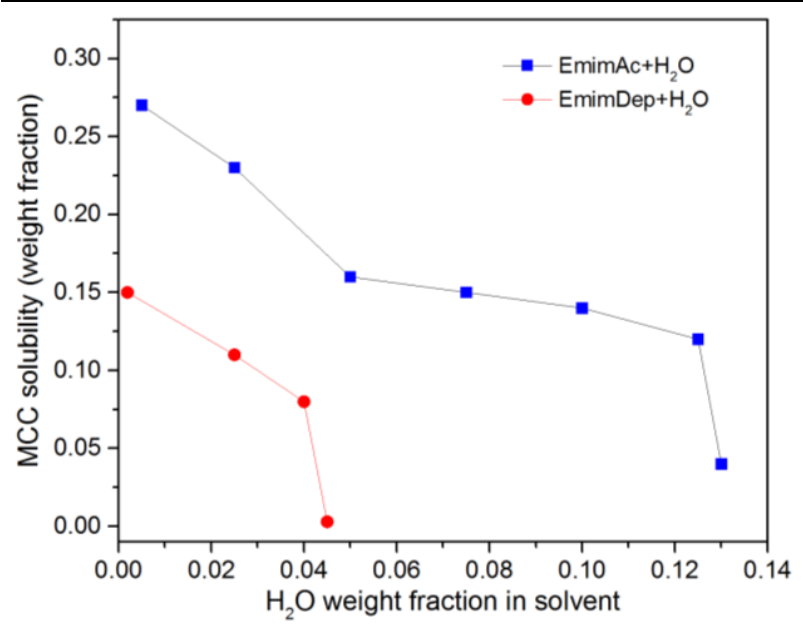

Figure 1 Experimental values of MCC solubility plotted against $\mathrm{H}_{2} \mathrm{O}$ weight fraction in solvent at $363.15 \mathrm{~K}$.

\subsection{EmimAc and EmimDep recycling processes}

Figures 2 and 3 illustrate spinning processes using EmimAc and EmimDep as solvents and with recycling of IL. The initial 
spinning solution derived from the measured solubility data are EmimAc $(87.5 \mathrm{~kg})+\mathrm{H}_{2} \mathrm{O}(12.5 \mathrm{~kg})+\mathrm{MCC}(13.6 \mathrm{~kg})$ in Figure 2 and EmimDep $(96 \mathrm{~kg})+\mathrm{H}_{2} \mathrm{O}(4 \mathrm{~kg})+\mathrm{MCC}(8.7 \mathrm{~kg})$ in Figure 3. By increasing the water content to $13 \mathrm{wt} \%$ in the case of EmimAc and to $4.5 \mathrm{wt} \%$ in the case of EmimDep, MCC will precipitate. However, the cellulose fiber (MCC) cannot be regenerated with these small amounts of excess water. In the spinning process, it was chosen to use an amount of deionized water corresponding to the mass of the spinning solution as coagulation bath in the regeneration process. After the cellulose fiber regeneration, the same quantity of washing water was used for washing EmimAc and EmimDep away from the wet fiber.

It was assumed that no cellulose was lost or recycled in the process. With a known amount of fiber, the water evaporated from the wet fiber could therefore be determined by the weight loss during the vacuum drying. According to the experiment, $48.0 \mathrm{~kg}$ water evaporated from the wet fibers in the EmimAc recycling process, and $48.2 \mathrm{~kg}$ in the EmimDep recycling process. The vacuum drying step took place at $353.15 \mathrm{~K}$ corresponding to a water saturation pressure of $0.0474 \mathrm{MPa}$. The experimental pressure was set to $0.015 \mathrm{MPa}$. Under these conditions, the fiber would be dried to a water activity, $a_{\mathrm{w}}$ of approximate 0.32 . It is assumed that this water activity is a result of the interaction of water with IL rather than the interaction of water with fiber. According to COSMO-RS, a water activity of 0.32 is obtained for a solution with 0.68 mole fraction water in EmimAc. For EmimDep $+\mathrm{H}_{2} \mathrm{O}$ the corresponding water mole fraction is 0.6. After drying, the mass of the dry fiber was $2.3 \mathrm{~kg}$ higher than the original mass of MCC in the EmimAc recycling process. In the EmimDep recycling process the same number was $3.6 \mathrm{~kg}$. To obtain these water mole fractions, the final amounts of IL and water in the dry fiber product were determined to be $1.6 \mathrm{~kg}$ EmimAc+0.7 $\mathrm{kg} \mathrm{H}_{2} \mathrm{O}$ in the EmimAc process and $3.0 \mathrm{~kg}$ EmimDep+0.6 $\mathrm{kg} \mathrm{H}_{2} \mathrm{O}$ in the EmimDep process.

The EmimAc and EmimDep concentrations in the regenerated solvent (solution 1, Figures 2 and 3 ) and in the washing water (solutions 2 and 3, Figures 2 and 3) were determined by electrical conductivity measurements. The EmimAc and EmimDep electrical conductivity standard curves are given in Figure 4. The measured electrical conductivities of solutions 1, 2, and 3 diluted 100 times are listed in Table 2. The concentrations and quantities of EmimAc and EmimDep in solutions 1,2 , and 3 were calculated from these calibration curves and are listed in Table 2. The amount of EmimAc recycled from these three solutions is $82.5 \mathrm{~kg}$, corresponding to $94.2 \%$ of the amount of IL used as solvent. For EmimDep $91 \mathrm{~kg}$ is recycled, corresponding to $94.8 \%$ of the initial amount of EmimDep.

The amounts of IL and water remaining with the dry fiber was also determined from a mass balance assuming that the dry fiber corresponds to the initial amount of MCC. These values are given in Figures 2 and 3 . These amounts are not in complete agreement with the amounts of IL recovered in solutions 1,2 , and 3 from Figures 2 and 3 . The difference is partly caused by the uncertainty in calculating the water activity using COSMORS. This water activity was used for calculating the mole fraction of water in the solvent remaining with the dry fiber.

The mole fraction of water in the EmimAc+ $\mathrm{H}_{2} \mathrm{O}$ solution, Figure 2, box (d) is 0.944 . In our previous study it was concluded that a solution with a water mole fraction below 0.708 is not suitable for recycling EmimAc by freeze crystallization of water. ${ }^{14} \mathrm{~A}$ water mole fraction of 0.708 corresponds to $85.9 \mathrm{~kg}$ EmimAc+44.0 $\mathrm{kg} \mathrm{H} \mathrm{H}_{2} \mathrm{O}$. Thus, $260.6 \mathrm{~kg}$ water can theoretically be removed as ice from a solution of $85.9 \mathrm{~kg} \mathrm{EmimAc+304.6 \textrm {kg }}$ $\mathrm{H}_{2} \mathrm{O}$. In order to further reduce the water content to $12.5 \mathrm{~kg}$ (Figure 2, box (g), $31.5 \mathrm{~kg}$ of water needs to be evaporated. Similarly for the EmimDep recycling process in Figure 3, the water mole fraction can be reduced from 0.957 to 0.682 by freezing of $254.1 \mathrm{~kg}$ water. Subsequently, $23.2 \mathrm{~kg}$ water has to be evaporated in the EmimDep recycling process. The amounts of components in each step of the EmimAc and EmimDep recycling processes are given in Figures 2 and 3. 


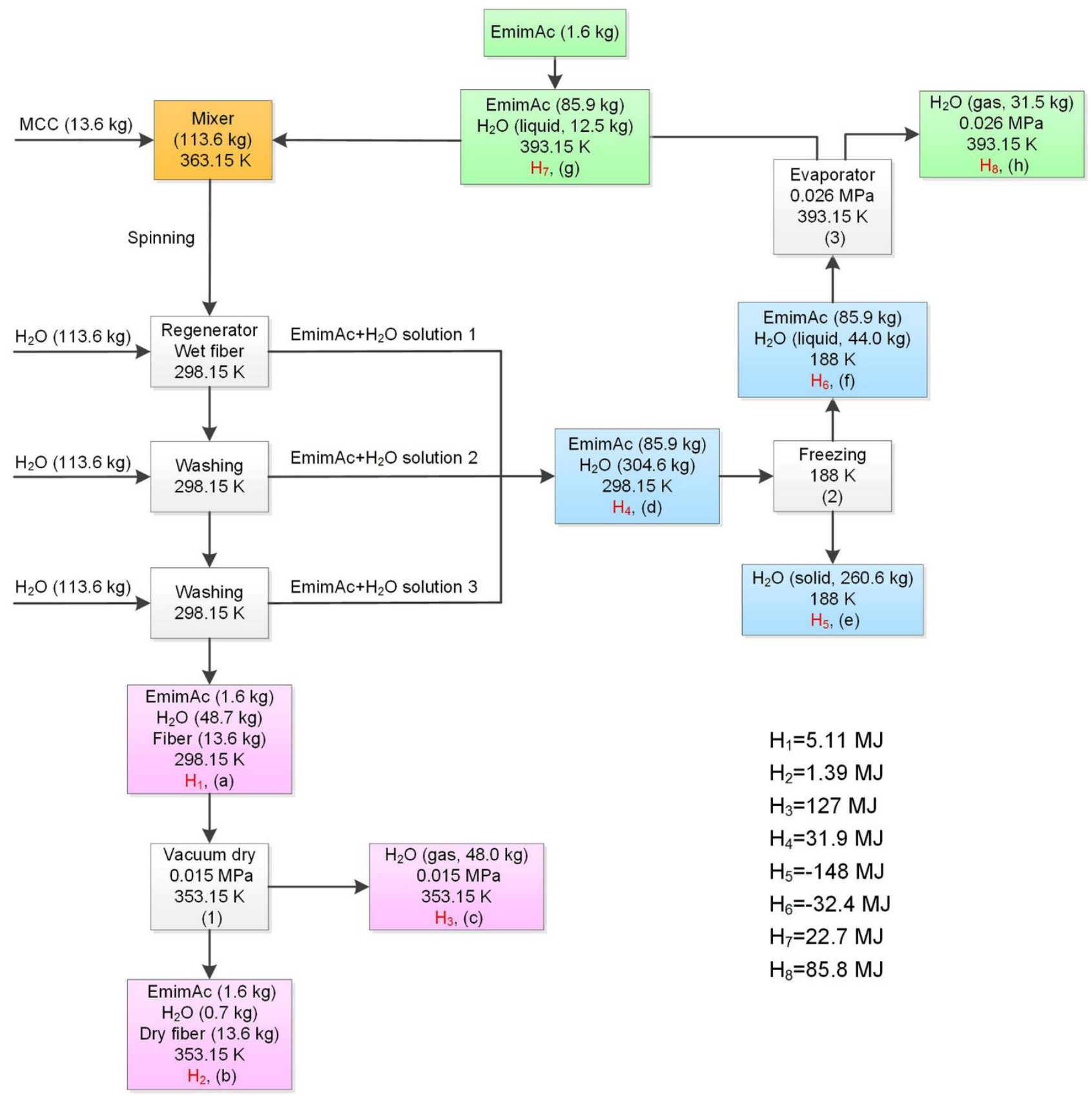

Figure 2 EmimAc recycling in a cellulose spinning process. $\mathrm{H}_{1}-\mathrm{H}_{8}$ are the enthalpies of the mixtures described in box (a) to box (h). 


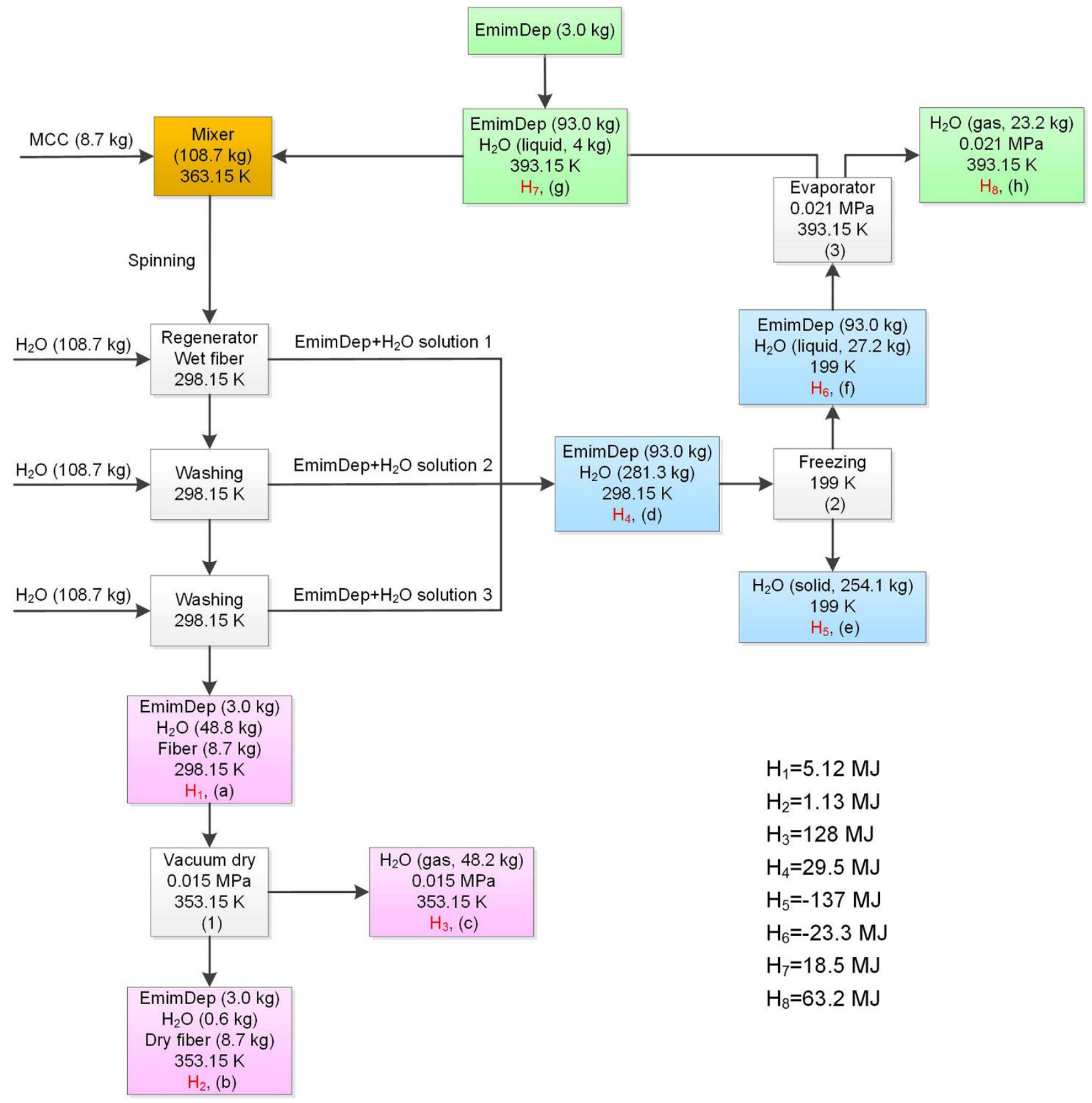

Figure 3 EmimDep recycling in a cellulose spinning process. $\mathrm{H}_{1}-\mathrm{H}_{8}$ are the enthalpies of the mixtures described in box (a) to box (h). 
Table 2 Electrical conductivity, quantity and recycling yield of EmimAc and EmimDep in solutions 1, 2 and 3.

\begin{tabular}{|c|c|c|c|}
\hline EmimAc & Solution 1 & solution 2 & solution 3 \\
\hline Electrical conductivity $(\mathrm{mS})^{*}$ & 1.50 & 0.498 & 0.203 \\
\hline EmimAc g/100 g $\left(\right.$ EmimAc $\left.+\mathrm{H}_{2} \mathrm{O}\right)$ & 42.0 & 12.7 & 4.08 \\
\hline Quantity in solution (kg) & 63.3 & 14.3 & 4.88 \\
\hline Recycling yield (wt\%) & 72.3 & 16.3 & 5.57 \\
\hline EmimDep & Solution 1 & solution 2 & solution 3 \\
\hline Electrical conductivity $(\mathrm{mS})^{*}$ & 0.914 & 0.408 & 0.168 \\
\hline EmimDep g/100 g (EmimDep $\left.+\mathrm{H}_{2} \mathrm{O}\right)$ & 47.2 & 20.3 & 7.50 \\
\hline Quantity in solution (kg) & 56.7 & 25.2 & 9.13 \\
\hline Recycling yield (wt\%) & 59.1 & 26.2 & 9.51 \\
\hline
\end{tabular}

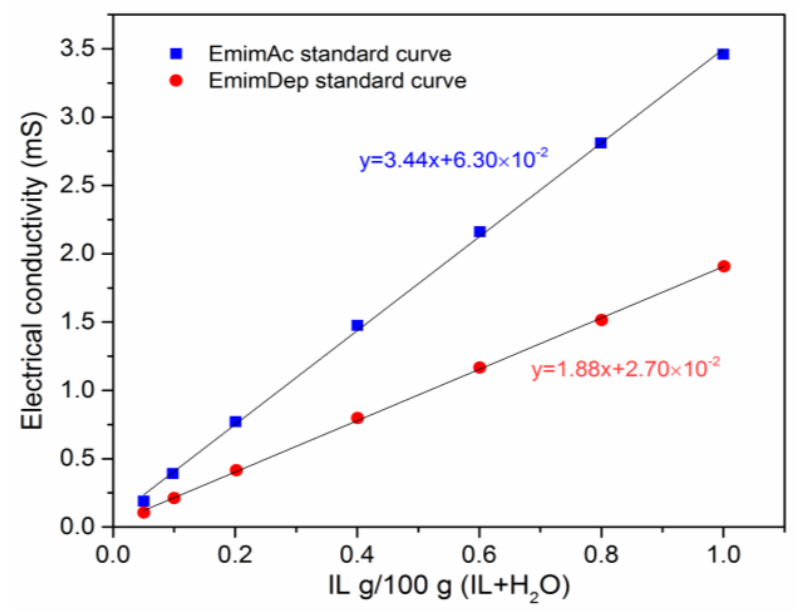

Figure 4 EmimAc and EmimDep electrical conductivity standard curves. The standard uncertainty of the electrical conductivity is $0.07 \mathrm{mS}$.

\subsection{Energy requirement for EmimAc and EmimDep recycling processes}

Table 3 gives the values of the heat capacity parameters and the specific enthalpy of EmimAc, EmimDep, and MCC valid in temperature ranges relevant for Figures 2 and 3 . Based on these values, the specific enthalpy of EmimAc and EmimDep in box (a), (b), (d), (f) and (g) in Figures 2 and 3 were calculated using equation 3. A reference temperature of $298.15 \mathrm{~K}$ was used for ILs and MCC. The enthalpies of EmimAc, EmimDep, and MCC in box (a) and (d) are therefore 0 . Specific enthalpy values for water and ice relevant for the processes in Figures 2 and 3 are listed in Table 4.

Process diagrams for recycling processes for EmimAc (Figure 6) and EmimDep (Figure 7) using only evaporation are given in the electronic supplementary information. Key numbers for the energy requirement of this process are given together with key numbers for the freeze crystallization+evaporation process in table 5 .

The main energy requiring steps in the freeze crystallization+ evaporation recycling processes in Figures 2 and 3 include the vacuum drying, the freeze crystallization, and the evaporation processes. For the cellulose spinning process using EmimAc as solvent, Figure 2, the energy consumption in the vacuum drying process is $123 \mathrm{MJ}$. The freeze crystallization process requires $212 \mathrm{MJ}$. The energy consumption of the evaporation process is $141 \mathrm{MJ}$. When EmimDep is used as solvent (Figure 3), the energy usage in the vacuum drying process is $124 \mathrm{MJ}$, the freezing process requires $190 \mathrm{MJ}$, and the evaporation process uses 105 MJ. The efficiency of a freezing process is typically $60 \%{ }^{27}$. The energy supplied to the freezing process in Figure 2 could therefore be as high as $354 \mathrm{MJ}$, and in Figure 3 the corresponding number could be $316 \mathrm{MJ}$. The total energy requirement for the vacuum drying process, the freezing process, and the evaporation process with EmimAc as solvent (Figure 2) is $618 \mathrm{MJ}$, which is equal to $45.4 \mathrm{MJ} / \mathrm{kg}$ cellulose fiber. The total energy requirement for EmimDep recycling in Figure 3 is $545 \mathrm{MJ}$ corresponds to $62.6 \mathrm{MJ} / \mathrm{kg}$ cellulose fiber.

If recycling of EmimAc and EmimDep are performed by the evaporation method, the energy usage in the vacuum drying process is the same as calculated for the freeze crystallization+evaporation method. To remove water from the solvent by evaporation, the energy requirement is $787 \mathrm{MJ}$ for EmimAc. For EmimDep the corresponding number is $745 \mathrm{MJ}$. Thus, the total energy usage for the EmimAc recycling process by evaporation is $910 \mathrm{MJ}$ corresponding to $66.9 \mathrm{MJ} / \mathrm{kg}$ cellulose fiber. The EmimDep recycling process by evaporation requires $869 \mathrm{MJ}$ corresponding to $99.9 \mathrm{MJ} / \mathrm{kg}$ cellulose fiber.

According to the energy balances, $21.5 \mathrm{MJ}$ per kg cellulose fiber can be saved by using the combined freeze crystallization+ evaporation process rather than evaporation only for recycling of EmimAc. The corresponding number is $37.3 \mathrm{MJ}$ per $\mathrm{kg}$ cellulose fiber that can be saved if EmimDep is recycled using 
freeze crystallization+evaporation. The energy balances therefore verify the hypothesis behind this work, namely that freeze crystallization+evaporation rather than evaporation for IL recycling will save a significant amount of energy.

In the EmimAc recycling process using freeze crystallization+ evaporation (Figure 2), the total quantity of water used in the regeneration and washing steps is $340.8 \mathrm{~kg}$. $260.6 \mathrm{~kg}$ water is recovered as ice and only $79.5 \mathrm{~kg}$ water is evaporated. The amount of cellulose fiber produced is $13.6 \mathrm{~kg}$. To produce $1 \mathrm{~kg}$ cellulose fiber requires the evaporation of $5.8 \mathrm{~kg}$ water in the drying and the recycling process when using EmimAc as solvent. When using EmimDep as solvent (Figure 3), $8.2 \mathrm{~kg}$ water needs to be evaporated per $\mathrm{kg}$ fiber in the drying and recycling process. It is therefore clear that the energy requirement of the IL recycling process depends on the type of IL.
Cai et $\mathrm{a}^{28}$ indicated that recycling of the amount of NMMO solvent required for producing $1 \mathrm{~kg}$ Lyocell fiber requires evaporation of 15-40 kg water. This amount only includes the recycling of solvent, not the drying of fiber. It therefore seems like using IL as solvent, and recovering the IL by freeze crystallization+evaporation will save a large amount of energy also compared to traditional cellulose processing.

Our previous work, ${ }^{14}$ shows that in the dilute region of aqueous solutions of ILs, ice starts forming when the solutions are cooled to their freezing points. A change in slope of the freezing point curve at increased concentration of IL indicates a change in solid phase which might be IL $n \mathrm{H}_{2} \mathrm{O}$. Therefore, ILs with a potential to dissolve cellulose can be partly regenerated by freeze crystallization in the concentration range where pure ice is the stable solid phase.

Table 3 Values of heat capacity, temperature slope $a$, and specific enthalpy of EmimAc, EmimDep, and MCC in Figures 2 and 3.

\begin{tabular}{cccccc}
\hline Name & $\begin{array}{c}C_{\mathrm{p}, 298.15 \mathrm{~K}} \\
\mathrm{~kJ} /(\mathrm{kg} \cdot \mathrm{K})\end{array}$ & $\begin{array}{c}a \\
\mathrm{~kJ} /\left(\mathrm{kg} \cdot \mathrm{K}^{2}\right)\end{array}$ & $\begin{array}{c}\text { box }(\mathrm{b}) \\
\mathrm{kJ} / \mathrm{kg}\end{array}$ & $\begin{array}{c}\mathrm{box}(\mathrm{f}) \\
\mathrm{kJ} / \mathrm{kg}\end{array}$ & $\begin{array}{c}\text { box }(\mathrm{g}) \\
\mathrm{kJ} / \mathrm{kg}\end{array}$ \\
\hline EmimAc & $1.89^{16}$ & $2.40 \times 10^{-3}$ & 108 & -194 & 190 \\
EmimDep & $1.74^{18}$ & $2.75 \times 10^{-3}$ & 99.9 & -159 & 178 \\
MCC & $1.20^{19}$ & $4.29 \times 10^{-3}$ & 72.5 & &
\end{tabular}

$a$ was calculated by equation 1 . Specific enthalpies were calculated with equation 3 . The specific enthalpies of EmimAc, EmimDep, and MCC in box (a) and (d) are 0.

Table 4 Specific enthalpy of water and ice relevant for Figures 2 and 3.

\begin{tabular}{|c|c|c|c|c|c|c|c|}
\hline Process & $\begin{array}{c}\mathrm{H}_{2} \mathrm{O}(\mathrm{l}) \\
\text { box (a) and (d) } \\
\mathrm{kJ} / \mathrm{kg}\end{array}$ & $\begin{array}{c}\mathrm{H}_{2} \mathrm{O}(\mathrm{l}) \\
\text { box (b) } \\
\mathrm{kJ} / \mathrm{kg}\end{array}$ & $\begin{array}{c}\mathrm{H}_{2} \mathrm{O} \text { (gas) } \\
\text { box (c) } \\
\mathrm{kJ} / \mathrm{kg}\end{array}$ & $\begin{array}{l}\mathrm{H}_{2} \mathrm{O}(\mathrm{l}) \\
\text { box (f) } \\
\mathrm{kJ} / \mathrm{kg}\end{array}$ & $\begin{array}{c}\mathrm{H}_{2} \mathrm{O}(\mathrm{I}) \\
\text { box (g) } \\
\mathrm{kJ} / \mathrm{kg}\end{array}$ & $\begin{array}{c}\mathrm{H}_{2} \mathrm{O} \text { (gas) } \\
\text { box (h) } \\
\mathrm{kJ} / \mathrm{kg}\end{array}$ & $\begin{array}{c}\mathrm{H}_{2} \mathrm{O} \text { (ice) } \\
\text { box (e) } \\
\mathrm{kJ} / \mathrm{kg}\end{array}$ \\
\hline Figure 2 & 105 & 335 & 2649 & -358 & 504 & 2724 & -569 \\
\hline Figure 3 & 105 & 335 & 2649 & -311 & 504 & 2725 & -538 \\
\hline
\end{tabular}

The specific enthalpy of water was calculated by NIST/ASME steam properties program. The water enthalpy in box (f) was calculated by equation 3. The ice enthalpy was calculated by equation 4 .

Table 5 Energy requirements for recycling EmimAc and EmimDep using a freeze crystallization+evaporation process and a process in which all water is removed by evaporation.

\begin{tabular}{|c|c|c|c|c|c|}
\hline $\begin{array}{c}\text { Freeze } \\
\text { crystallization+ } \\
\text { evaporation }\end{array}$ & $\begin{array}{l}\text { Vacuum drying } \\
\text { (MJ) }\end{array}$ & $\begin{array}{l}\text { Freezing } \\
\text { (MJ) }\end{array}$ & $\begin{array}{c}\text { Evaporation } \\
\text { (MJ) }\end{array}$ & $\begin{array}{l}\text { Total } \\
\text { (MJ) }\end{array}$ & $\begin{array}{l}\text { Energy consumption } \\
\text { per kg cellulose (MJ) }\end{array}$ \\
\hline EmimAc & 123 & $354 *$ & 141 & 618 & 45.4 \\
\hline EmimDep & 124 & $316^{*}$ & 105 & 545 & 62.6 \\
\hline Evaporation & $\begin{array}{l}\text { Vacuum drying } \\
\text { (MJ) }\end{array}$ & $\begin{array}{l}\text { Freezing } \\
\text { (MJ) }\end{array}$ & $\begin{array}{c}\text { Evaporation } \\
\text { (MJ) }\end{array}$ & $\begin{array}{l}\text { Total } \\
\text { (MJ) }\end{array}$ & $\begin{array}{l}\text { Energy consumption } \\
\text { per kg cellulose (MJ) }\end{array}$ \\
\hline EmimAc & 123 & - & 787 & 910 & 66.9 \\
\hline EmimDep & 124 & - & 745 & 869 & 99.9 \\
\hline
\end{tabular}

*The freezing process is assumed to have an efficiency of $60 \%$ while the vacuum drying and the evaporation processes are assumed to have efficiencies of $100 \%$.

The total energy requirement for recycling EmimAc corresponds to producing $13.6 \mathrm{~kg}$ cellulose fiber. The total energy requirement for recycling EmimDep corresponds to producing $8.7 \mathrm{~kg}$ cellulose fiber. 


\subsection{The morphology and crystallinity analysis of regenerated MCC}

The morphologies of the original MCC (dry) and regenerated MCC (dry) were observed by SEM (Figure 5). Figure 5 (a) shows the original MCC used in the experiment. Figure 5 (b) is MCC regenerated after dissolution in EmimAc with a water mole fraction of approximately $0.2\left(\right.$ EmimAc $\left.+5 w t \% \mathrm{H}_{2} \mathrm{O}\right)$. Figure 5 (c) is $\mathrm{MCC}$ regenerated after dissolution in EmimAc with a water mole fraction of approximately 0.3 (EmimAc+7.5 wt\% $\mathrm{H}_{2} \mathrm{O}$ ). Figure 5 (d) is MCC regenerated after dissolution in EmimDep with a water mole fraction of approximately 0.2 (EmimDep+2.5 wt\% $\mathrm{H}_{2} \mathrm{O}$ ). With increasing water mole fraction in EmimAc+ $\mathrm{H}_{2} \mathrm{O}$ mixtures, the surface morphology of the regenerated MCC changes distinctly (Figure 5 ). With the same water mole fraction of approximately 0.2 in EmimAc (with 5 wt\% $\mathrm{H}_{2} \mathrm{O}$ ) and in EmimDep (with $2.5 \mathrm{wt} \% \mathrm{H}_{2} \mathrm{O}$ ) the surface morphologies of the regenerated MCC were also different. The SEM result indicates that the water content and the type of IL significantly affect the morphology and the properties of the fibers.

The X-ray diffraction (XRD) analysis is given in Figure 6. The original MCC displays a strong peak around $2 \theta=22.8^{\circ}$, corresponding to the $(002)$ crystal plane of cellulose, as well as a composite peak corresponding to the $(101)$ and $\left(10^{-}, 1\right)$ crystal planes at $2 \theta=15^{\circ}$ and $15.5^{\circ}$ approximately. The intensity of the (002) plane decreases dramatically for MCC treated with EmimAc $+\mathrm{H}_{2} \mathrm{O}$ and EmimDep $+\mathrm{H}_{2} \mathrm{O}$. No distinct peak remains for the $(101)$ and $\left(10^{-}, 1\right)$ planes, which illustrates that the crystallinity of cellulose is greatly disrupted after the dissolution and regeneration from EmimAc $+\mathrm{H}_{2} \mathrm{O}$ and EmimDep $+\mathrm{H}_{2} \mathrm{O}$. This disruption ability is diminished with the addition of water in EmimAc. These results are in agreement with the results obtained in the study by Doherty et al. ${ }^{29}$
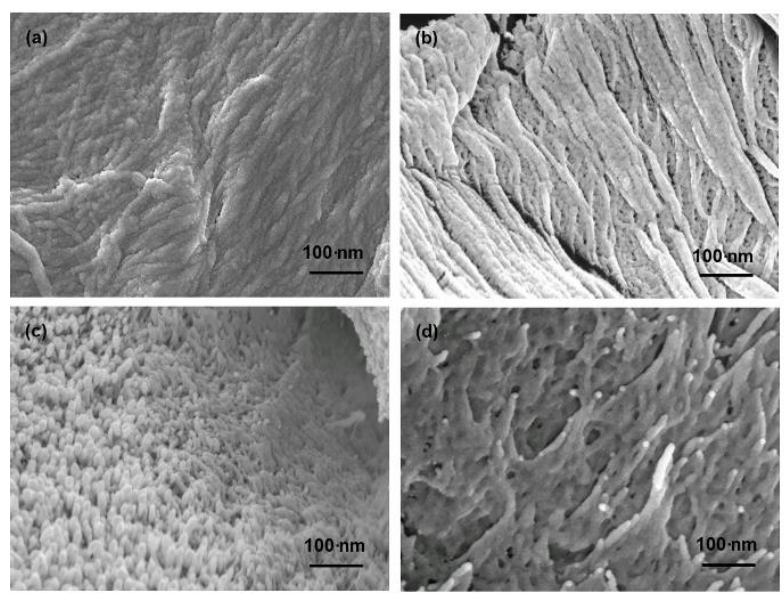

Figure 5 (a) Morphology of original MCC, (b) MCC regenerated from EmimAc with water mole fraction of $0.2\left(5 \mathrm{wt} \% \mathrm{H}_{2} \mathrm{O}\right)$, (c) $\mathrm{MCC}$ regenerated from EmimAc with water mole fraction of 0.3 (7.5 wt\% $\mathrm{H}_{2} \mathrm{O}$ ), (d) $\mathrm{MCC}$ regenerated from EmimDep with water mole fraction of $0.2\left(2.5 w t \% \mathrm{H}_{2} \mathrm{O}\right)$.

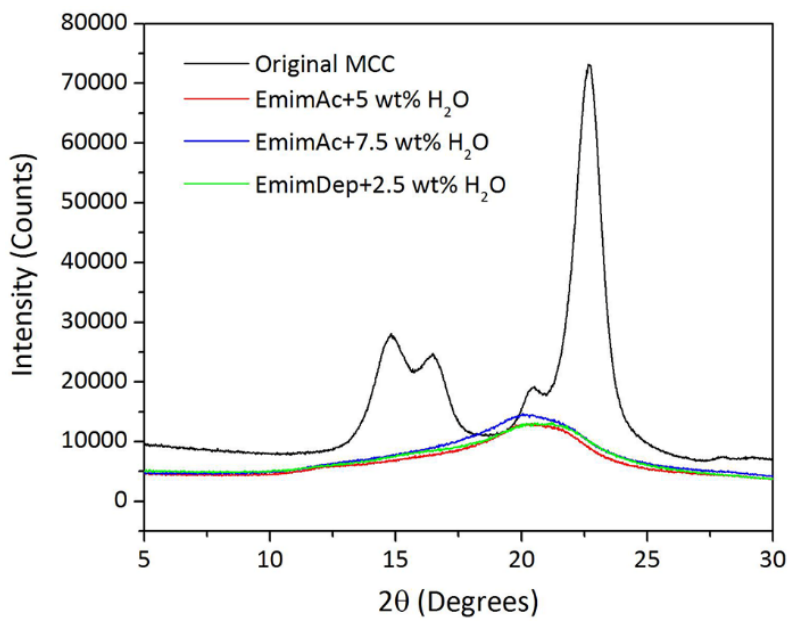

Figure 6 XRD of original MCC and regenerated MCCs.

\section{Experimental}

\subsection{Chemical reagents}

1-ethyl-3-methylimidazolium Acetate (EmimAc, $170.21 \mathrm{~g} / \mathrm{mol}$ ) and 1-ethyl-3-methylimidazolium Diethyl phosphate (EmimDep, $264.26 \mathrm{~g} / \mathrm{mol}$ ) which have the same cation and different anions were selected for this study. In our previous work it has been verified that these two ILs have a high capacity for cellulose dissolution. ${ }^{26}$ EmimAc (99 wt\%), was purchased from Shanghai Cheng Jie Chemical Co. LTD (Shanghai, China), and EmimDep was synthesized in one step. The synthetic method and the purity analysis of EmimDep was given in the supporting information of our previous work. ${ }^{26}$ The structures of EmimDep was confirmed by its ${ }^{1} \mathrm{H}$ and ${ }^{13} \mathrm{C}$ NMR spectra using a Bruker 600 spectrometer. Characteristic peaks and ${ }^{1} \mathrm{H}$ and ${ }^{13} \mathrm{C}$ NMR data of EmimDep was shown in the supporting information of our previous work. $^{14}$ Cellulose was microcrystalline cellulose (MCC) purchased from Sinopharm Chemical Reagent Co. Ltd. (Shanghai, China).

\subsection{Cellulose dissolution and IL recycling procedures}

EmimAc and EmimDep were mixed with different amounts of water for assessing the solubility of MCC at $363.15 \mathrm{~K}$. The MCC was dried at $353.15 \mathrm{~K}$ under vacuum for $48 \mathrm{~h}$ before use. An initial amount of MCC of approximately $0.05 \mathrm{~g}$ was added to the $\mathrm{IL}+\mathrm{H}_{2} \mathrm{O}$ mixtures $(5 \mathrm{~g})$ at the beginning. Subsequently, MCC was added stepwise in $0.05 \mathrm{~g}$ portions until the solubility limit was reached. When the MCC start solubility is less than $0.05 \mathrm{~g}$, the stepwise added amount of MCC was changed to $0.005 \mathrm{~g}$ portions until the solubility limit was reached. An OLYMPUS BX 51 optical microscope was used to assess the dissolution of MCC in the different $\mathrm{IL}+\mathrm{H}_{2} \mathrm{O}$ mixtures. When $\mathrm{MCC}$ could be observed under the optical microscope without dissolving after 12 hours $26,30,31$ the solubility limit had been exceeded.

The recycling process was performed at laboratory scale, and then scaled-up proportional to the experimental amounts. The recycling process included the following steps: 1 . Different amounts of MCC was dissolved in $\mathrm{IL}+\mathrm{H}_{2} \mathrm{O}$ mixtures at $363.15 \mathrm{~K}$ 
to form the spinning solution. 2. The spinning solution was placed into a spinning equipment (Longer Pump, LSP01-1A) to make the cellulose fiber. A single hole spinneret needle was connected to a coagulation bath using deionized water as the regeneration solvent. After the cellulose regeneration, the cellulose fiber $+\mathrm{IL}+\mathrm{H}_{2} \mathrm{O}$ mixture was separated into wet cellulose fiber and aqueous IL solution. 3. The wet cellulose fiber was washed twice using deionized water to remove IL. 4. The amounts of IL in the solutions were determined by measuring the electrical conductivity. The three solutions were mixed and cooled to remove water as ice by freezing (prediction). Remaining water was evaporated to make the IL ready for recycling (prediction). 5. Finally, the wet fiber was dried in vacuum drying oven at the temperature of $353.15 \mathrm{~K}$ and the pressure of $0.015 \mathrm{MPa}$ to remove water from it. The recycling procedures of EmimAc and EmimDep are illustrated in Figures 2 and 3.

In step 2 and 3, the electrical conductivities of the regenerated solvent and two batches of wash solutions were measured. A conductivity meter (Orion, 136S) with automatic data logging was used. Electrical conductivity calibration curves of aqueous EmimAc and EmimDep solutions were first determined. The amounts of EmimAc and EmimDep used for measuring the electrical conductivity calibration curve were approximately $0.05,0.1,0.2,0.4,0.6,0.8$ and $1 \mathrm{~g}$ per $100 \mathrm{~g}$ solution. The aqueous EmimAc and EmimDep solutions in step 2 and 3 were diluted 100 times in order to be within the concentration range of the calibration curves. The quantities of EmimAc and EmimDep in the regenerated solvent and in the washing solutions were determined according to these calibration curves. The electrical conductivity of each sample was measured more than 15 minutes until a consistent value was reached.

\subsection{SEM and XRD analysis for regenerated MCC}

The morphology of the original $\mathrm{MCC}$ and the selected regenerated $\mathrm{MCCs}$ obtained after using EmimAc+ $\mathrm{H}_{2} \mathrm{O}$ and EmimDep $+\mathrm{H}_{2} \mathrm{O}$ as solvents were observed by SEM (JSM 6700F, Japan, $5.0 \mathrm{kV}$ ). The sample was sputtered with platinum for better observation using JEC-3000FC auto fine coater. The current and the sputtering time were set to $20 \mathrm{~mA}$ and $150 \mathrm{~s}$ respectively. XRD of the original MCC and of the regenerated MCC was employed to examine the crystalline structures of original MCC and regenerated MCC. Data were obtained using a Bruker D8 Focus instrument, and the $\mathrm{X}$-ray tube was operated at $40 \mathrm{kV}$ and $200 \mathrm{~mA}$ with $2 \theta$ ranging from $5^{\circ}$ to $30^{\circ}$ at a scan speed of $0.05 \mathrm{~s}^{-1}$.

\section{Conclusion}

In this study, the solubility of MCC in two selected ILs (i.e. in $\mathrm{I} \mathrm{L}+\mathrm{H}_{2} \mathrm{O}$ mixtures) as a function of water content was measured at $363.15 \mathrm{~K}$. The MCC solubility decreases gradually as water is added and then suddenly reaches a solubility limit. The viscosity of the $\mathrm{IL}+\mathrm{H}_{2} \mathrm{O}$ mixtures were also taken into account, hence EmimAc with 12.5 wt\% $\mathrm{H}_{2} \mathrm{O}$ and EmimDep with 4 wt\% $\mathrm{H}_{2} \mathrm{O}$ were chosen as solvents for cellulose spinning with IL recycling. The energy usage of two processes: freeze crystallization+ evaporation versus evaporation of $\mathrm{H}_{2} \mathrm{O}$ from ILs $+\mathrm{H}_{2} \mathrm{O}$ mixtures was evaluated for recycling of the ILs. A higher initial amount of $\mathrm{H}_{2} \mathrm{O}$ was used in practice for the cellulose solubilisation and spinning using EmimAc as compared to using EmimDep as solvent. Still, the higher solubility of cellulose (MCC) in EmimAc meant that less energy was required for freeze crystallization+evaporation of $\mathrm{H}_{2} \mathrm{O}$ to recover and recycle the IL from EmimAc $+\mathrm{H}_{2} \mathrm{O}$ mixtures than from EmimDep $+\mathrm{H}_{2} \mathrm{O}$ mixtures (45.4 MJ vs $62.6 \mathrm{MJ}$ per kg dry cellulose fiber). Using electrical conductivity measurement, it was verified that $94.2 \mathrm{wt} \%$ of EmimAc and 94.8 wt\% of EmimDep could be recovered after cellulose spinning.

It was found that using freeze crystallization+evaporation for recycling of EmimAc and EmimDep, respectively, can save a significant amount of energy compared to a process where all water is removed by evaporation, namely $21.5 \mathrm{MJ}$ for EmimAc and 37.3 MJ for EmimDep per kg dry cellulose produced. This new IL recycling method not only saves energy for IL recycling compared to evaporation, but is also much more energy efficient than conventional cellulose fiber production methods, such as the NMMO process. The freeze crystallization+ evaporation method may also be applied to other processes requiring separation of $\mathrm{IL}+\mathrm{H}_{2} \mathrm{O}$ mixtures and thus potentially result in energy saving in multiple cellulose processing applications.

\section{Conflicts of interest}

There are no conflicts of interest to declare

\section{Acknowledgements}

We would like to sincerely thank Liangyu Ma and Wenjun Wang for helping with the MCC solubility and MCC morphological properties study. This work was supported by the Department of Chemical and Biochemical Engineering, Technical University of Denmark and CAS/SAFEA International Partnership Program for Creative Research Teams (Grant No. 20140491518), General Program of National Natural Science Foundation of China (Grant No. 21576262 and 2157060191).

\section{References}

1 X. J. Li, N. K. Li, J. G. Xu, X. Q. Duan, Y. S. Sun and Q. Zhao, J. Appl. Polym. Sci., 2014, 131, 742-751.

2 A. R. Xu, J. J. Wang and H. Y. Wang, Green Chem., 2010, 12, 268-275.

3 J. H. Hong, M. K. Ku, Y. Ahn, H. J. Kim and H. Kim, Fiber polym., 2013, 14, 2015-2019.

4 L. F. Sun, J. Y. Chen, W. Jiang and V. Lynch, Carbohyd. Polym., 2015, 118, 150-155.

5 Z. Q. Luo, A. Q. Wang, C. Z. Wang, W. C. Qin, N. N. Zhao, H. Z. Song and J. G. Gao, J. Mater. Chem. A, 2014, 2, 7327-7336.

6 C. Zhu, J. Chen, K. K. Koziol, J. W. Gilman, P. C. Trulove and S. S. Rahatekar, Express polym. Let., 2014, 8, 154-163. 
7 Y. L. Zhao, X. M. Liu, J. J. Wang and S. J. Zhang, J. Phys. Chem. B, 2013, 117, 9042-9049.

8 J. G. Lynam, G. I. Chow, C. J. Coronella and S. R. Hiibel, Chem. Eng. J., 2016, 288, 557-561.

9 X. Liu, Y. Nie, X. L. Meng, Z. L. Zhang, X. P. Zhang and S. J. Zhang, RSC Adv., 2017, 7, 1981-1988.

10 T. Fukuyama, M. Shinmen, S. Nishitani, M. Sato and I. Ryu, Org. lett., 2002, 4, 1691-1694.

11 J. F., Jr. Birdwell, J. McFarlane, R. D. Hunt, H. M. Luo, D. W. DePaoli, D. L. Schuh and S. Dai, Sep. Sci. Technol., 2006, 41, 2205-2223.

12 L. A. Blanchard and J. F. Brennecke, Ind. Eng. Chem. Res., 2001, 40, 287-292.

13 B. Wu, W. W. Liu, Y. M. Zhang and H. P. Wang, Chem. Eur. J., 2009, 15, 1804-1810.

14 Y. R. Liu, A. S. Meyer, Y. Nie, S. J. Zhang, Y. S. Zhao, P. L. Fosbøl and K. Thomsen, J. Chem. Eng. Data, 2017, 62, 2374-2383.

15 R. Vaessen, M. Seckler and G. J. Witkamp, Ind. Eng. Chem. Res., 2003, 42, 4874-4880.

16 M. G. Freire, A. R. R. Teles, M. A. A. Rocha, B. Schröder, C. M. S. S. Neves, P. J. Carvalho, D. V. Evtuguin, L. M. N. B. F. Santos and J. A. P. Coutinho, J. Chem. Eng. Data, 2011, 56, 48134822.

17 C. Su, X. Y. Liu, C. Y. Zhu and M. G. He, Fluid Phase Equilib., 2016, 427, 187-193.

18 C. M. Tenney, M. Massel, J. M. Mayes, M. Sen, J. F. Brennecke and E. J. Maginn, J. Chem. Eng. Data, 2014, 59, 391-399.

19 IL Thermo: Ionic Liquids Database. http://ilthermo.boulder.nist.gov/. (accessed December 2017).

20 A. V. Blokhin, O. V. Voitkevich, G. J. Kabo, Y. U. Paulechka, M. V. Shishonok, A. G. Kabo and V. V. Simirsky, J. Chem. Eng. Data., 2011, 56, 3523-3531.

21 Enthalpy of fusion. https://en.wikipedia.org/wiki/Enthalpy_of_fusion. (accessed August 2017).

22 M. W. Arshad, P. L. Fosbøl, N. von Solms and K. Thomsen, J. Chem. Eng. Data, 2013, 58, 1918-1926.

23 K. A. Le, R. Sescousse and T. Budtova, Cellulose, 2012, 19, 4554.

24 D. L. Minnick, R. A. Flores, M. R. DeStefano and A. M. Scurto, J. Phys. Chem. B, 2016, 120, 7906-7919.

25 C. Olsson, A. Idström, L. Nordstierna and G. Westman, Carbohyd. Polym., 2014, 99, 438-446.

26 Y. R. Liu, K. Thomsen, Y. Nie, S. J. Zhang and A. S. Meyer, Green Chem., 2016, 18, 6246-6254.

27 Liquid air energy network, Chapter 2: An introduction to liquid air: http://liquidair.org.uk/full-report/report-chaptertwo. (accessed August 2017).

28 J. Cai and Z. Q. Han, CN 103046167 A, 2013.04.17.

29 T. V. Doherty, M. Mora-Pale, S. E. Foley, R. J. Linhardt and J. S. Dordick, Green Chem., 2010, 12, 1967-1975.

30 A. Casas, S. Omar, J. Palomar, M. Oliet, M. V. Alonso and F. Rodriguez, RSC Adv., 2013, 3, 3453-3460.

31 L. Liu, M. T. Ju, W. Z. Li and Q. D. Hou, Carbohyd. Polym., 2013, 98, 412-420. 